\title{
Changes in Gene Expression Linked to Methamphetamine-Induced Dopaminergic Neurotoxicity
}

\author{
Tao Xie, ${ }^{1}$ Liqiong Tong, ${ }^{1}$ Tanya Barrett, ${ }^{3}$ Jie Yuan, ${ }^{1}$ George Hatzidimitriou, ${ }^{1}$ Una D. McCann, ${ }^{2}$ \\ Kevin G. Becker, ${ }^{3}$ David M. Donovan, ${ }^{3}$ and George A. Ricaurte ${ }^{1}$ \\ Departments of ${ }^{1}$ Neurology and ${ }^{2}$ Psychiatry and Behavioral Sciences, Johns Hopkins University School of Medicine, \\ Baltimore, Maryland 21224, and the ${ }^{3}$ Research Resources Branch, Intramural Research Program, National Institute on \\ Aging, National Institutes of Health, Baltimore, Maryland 21224-6825
}

The purpose of these studies was to examine the role of gene expression in methamphetamine (METH)-induced dopamine (DA) neurotoxicity. First, the effects of the mRNA synthesis inhibitor, actinomycin-D, and the protein synthesis inhibitor, cycloheximide, were examined. Both agents afforded complete protection against METH-induced DA neurotoxicity and did so independently of effects on core temperature, DA transporter function, or METH brain levels, suggesting that gene transcription and mRNA translation play a role in METH neurotoxicity. Next, microarray technology, in combination with an experimental approach designed to facilitate recognition of relevant gene expression patterns, was used to identify gene products linked to METH-induced DA neurotoxicity. This led to the identification of several genes in the ventral midbrain associated with the neurotoxic process, including genes for energy metabolism [cytochrome $c$ oxidase subunit 1 (COX1), reduced nicotinamide adenine dinucleotide ubiquinone oxidoreductase chain 2, and phosphoglycerate mutase B], ion regulation (members of sodium/hydrogen exchanger and sodium/bile acid cotransporter family), signal transduction (adenylyl cyclase III), and cell differentiation and degeneration ( $N$-myc downstreamregulated gene 3 and tau protein). Of these differentially expressed genes, we elected to further examine the increase in COX1 expression, because of data implicating energy utilization in METH neurotoxicity and the known role of COX1 in energy metabolism. On the basis of time course studies, Northern blot analyses, in situ hybridization results, and temperature studies, we now report that increased COX1 expression in the ventral midbrain is linked to METH-induced DA neuronal injury. The precise role of COX1 and other genes in METH neurotoxicity remains to be elucidated.

Key words: amphetamines; neurotoxicity; dopamine; neurodegeneration; cytochrome c oxidase; microarray
Despite considerable investigation (Gibb et al., 1994; Lew et al., 1997), the mechanisms underlying the neurotoxic effects of methamphetamine (METH) on brain dopamine (DA) neurons remain unknown. However, a considerable body of data attests to the importance of DA transporter (DAT) function and temperature. The essential role of the DAT in METH-induced DA neurotoxicity has been demonstrated by the observation that DAT inhibitors afford complete neuroprotection (Ricaurte et al., 1984; Marek et al., 1990a,b; Pu et al., 1994) and the finding that DAT knock-out mice are insensitive to METH neurotoxicity (Fumagalli et al., 1998). The importance of temperature has been documented by studies demonstrating that decreases in core temperature protect against METH neurotoxicity, whereas increases in core temperature exacerbate the toxicity (Bowyer et al., 1994; Miller and O'Callaghan, 1994; Albers and Sonsalla, 1995; Ali et al., 1996). Furthermore, there is evidence that at least part of the effect of temperature on METH neurotoxicity is mediated at the level of the DAT (Xie et al., 2000). More recent studies have also implicated energy metabolism (Huang et al., 1997;

\footnotetext{
Received Aug. 10, 2001; revised Oct. 4, 2001; accepted Oct. 4, 2001.

This work was supported by National Institute on Drug Abuse/National Institutes of Health Grants DA13790, DA09487, DA00206, and DA10217 (G.A.R.). We also thank Christopher Cheadle, William H. Wood III, Seajeong Kim, Diane Teichberg, and Brian Callahan for their kind assistance with various aspects of this work.

Correspondence should be addressed to Dr. George A. Ricaurte, Department of Neurology, Johns Hopkins Medical Institutions, 5501 Hopkins Bayview Circle, Room 5B.71E, Baltimore, MD 21224. E-mail: ricaurte@jhmi.edu.

Copyright (C) 2001 Society for Neuroscience $0270-6474 / 01 / 220274-10 \$ 15.00 / 0$
}

Stephans et al., 1998; Burrows et al., 2000a) and possibly ion dysregulation (Callahan et al., 2001) in the METH-induced DA neurotoxic process.

Primarily because of technical barriers, the possibility that gene expression might be involved in METH neurotoxicity has been relatively unexplored. However, with the recent development of microarray technology, it is now possible to rapidly screen large numbers of potentially relevant genes in biological processes. Indeed, for the study of DA neurotoxicity and other neuropsychiatric conditions involving DA neurons, we have recently developed "DA" and "neuronal" microarrays and have used them to identify a number of mRNA changes in the context of METHinduced DA neurotoxicity (Barrett et al., 2001). However, whether any of the gene expression changes that we and others (Merchant et al., 1994; Smith and McGinty, 1994; Wang and McGinty, 1995; Sheng et al., 1996; Badiani et al., 1998, 1999; Kodama et al., 1998; Jayanthi et al., 1999; Cadet et al., 2001) have identified after METH administration are directly linked to the neurotoxic process has yet to be established.

An early study (Finnegan and Karler, 1992) showed that protein synthesis inhibitors such as cycloheximide could prevent METH-induced DA neurotoxicity, thus raising the possibility that translation of a new gene product might be involved in the neurotoxic process. The purpose of the present studies was to evaluate more directly the role of gene expression in METHinduced DA neurotoxicity. In particular, we sought to (1) first confirm and extend the findings of Finnegan and Karler (1992) by 
eliminating possible confounding effects of cycloheximide on core temperature, DAT function, or brain METH levels; (2) use the transcription inhibitor, actinomycin-D, to determine whether gene expression is required, in fact, for the expression of METHinduced DA neurotoxicity and, if so, (3) use microarray technology, in combination with an experimental approach designed to facilitate recognition of relevant gene expression patterns, to identify gene products directly linked to METH-induced DA neuronal damage; and (4) use Northern analysis, in situ hybridization techniques, and neurotoxicological approaches to further link candidate genes to the METH-induced DA neurotoxicity.

\section{MATERIALS AND METHODS}

Drugs and chemicals. $\left[{ }^{3} \mathrm{H}\right] \mathrm{DA}$ and $\left[{ }^{3} \mathrm{H}\right]$ WIN 35,428 were purchased from New England Nuclear (Boston, MA). Methamphetamine (METH) hydrochloride and cocaine hydrochloride were obtained from the National Institute on Drug Abuse (Baltimore, MD). DA hydrochloride, cycloheximide, actinomycin-D, polyA, and diethylpyrocarbonate (DEPC) were purchased from Sigma (St. Louis, MO). The radioimmunoassay (RIA) kit for METH was purchased from the Diagnostic Products Corporation (Los Angeles, CA). RNAzol B was obtained from Tel-Test (Friendwood, TX). ${ }^{33} \mathrm{P}$-dCTP and the RNA color detection kit were purchased from Amersham Biosciences (Piscataway, NJ), polyT, and Microhyb hybridization buffer were made by Research Genetics (Huntsville, AL), and human Cot-1 DNA, Superscript II RNase $\mathrm{H}^{-}$Reverse Transcriptase, RNaseOUT Recombinant Inhibitor, $20 \times$ SSC, and 10\% SDS were purchased from Life Technologies (Grand Island, NY). The SP-30 column was manufactured by Bio-Rad (Hercules, CA), and primers were obtained from DNA Core Facility at Johns Hopkins Medical Institutions (Baltimore, MD). The PCR kit and $\beta$-actin cDNA probe were obtained from Clontech (Palo Alto, CA). The RNALater solution and the in vitro transcription kit were purchased from Ambion (Austin, TX). The RNeasy Mini kit was purchased from Qiagen (Valencia, CA). The "Primer-a-Gene" labeling system was purchased from Promega (Madison, WI). The dopamine array and neuronal array were provided by the Microarray Unit, National Institute of Aging (Baltimore, MD).

Animals. Male albino Swiss-Webster mice weighing 20-25 gm were purchased from Taconic (Germantown, NY). Choice of the mouse as the experimental animal for these studies was based on the consideration that, in the mouse, METH is selectively toxic to DA neurons (i.e., 5-HT neurons are typically not affected) (Gibb et al., 1994; Lew et al., 1997; Callahan et al., 1998). Animals were housed individually in clear acrylic cages in a temperature-controlled room $\left(22 \pm 1^{\circ} \mathrm{C}\right)$. All animal care and experimental manipulations were approved by the Institutional Animal Care and Use Committee at the Johns Hopkins University School of Medicine and were in accordance with the National Institutes of Health Guide for the Care and Use of Laboratory Animals. The facility for housing and care of the animals is accredited by the American Association for the Assessment and Accreditation of Laboratory Animal Care.

Cycloheximide studies. The effects of cycloheximide on METHinduced DA neurotoxicity were tested in three different experiments. In the first experiment, designed to evaluate possible confounding effects of temperature, four groups of mice ( $n=5$ per group) were used: (1) vehicle controls, (2) METH alone (45 mg/kg, s.c.), (3) cycloheximide alone $(150 \mathrm{mg} / \mathrm{kg}$, s.c.), and (4) METH (45 mg/kg, s.c.) plus cycloheximide $(150 \mathrm{mg} / \mathrm{kg}$, s.c., $0.5 \mathrm{hr}$ before METH). The dose of cycloheximide was selected on the basis of previous studies (Finnegan and Karler, 1992). The potentially confounding hypothermic effects of cycloheximide were eliminated by performing the studies in a warm environment. Rectal temperatures were measured using a BAT-12 thermometer coupled to a RET-3 mouse rectal probe with the resolution of $0.1^{\circ} \mathrm{C}$ (Physitemp Instruments, Clifton, NJ). Core temperature of mice treated with cycloheximide plus METH was yoked to that of mice administered METH alone by manipulating ambient temperature, as described previously (Yuan et al., 2001). All mice were killed 1 week after treatment for measurement of striatal DA axonal markers, as below.

In the second experiment, designed to rule out the possibility that the neuroprotective effects of cycloheximide might be secondary to DAT blockade, DAT function was measured in synaptosomes prepared from striatal tissue harvested from mice treated with cycloheximide $1,1.5$, and $2.5 \mathrm{hr}$ previously. This time frame corresponds to the time points of 0.5 , 1 , and $2 \mathrm{hr}$ after METH administration (because of the $0.5 \mathrm{hr}$ stagger in drug administration), as described below.
In a third experiment, designed to rule out the possibility that cycloheximide might alter METH pharmacokinetics, striatal concentrations of METH were measured 0.5 and $2 \mathrm{hr}$ after combined treatment with cycloheximide and METH, times at which peak levels of METH were anticipated.

Actinomycin-D studies. To examine the effects of the mRNA synthesis inhibitor, actinomycin-D, on METH neurotoxicity, four groups $(n=5$ per group) of mice were used: (1) vehicle controls, (2) METH alone (45 $\mathrm{mg} / \mathrm{kg}$, s.c.), (3) actinomycin-D alone $(0.5 \mathrm{mg} / \mathrm{kg}$, i.p.), and (4) METH (45 mg/kg, s.c.) plus actinomycin-D (0.5 mg/kg, i.p., 2 hr before METH). To rule out potential confounds of temperature, actions at the DAT, and METH pharmacokinetics, additional studies were conducted using similar methods as those described above for cycloheximide.

Microarray studies. To identify relevant gene expression patterns, microarray studies were performed in combination with a targeted pharmacological strategy designed to facilitate recognition of changes in gene expression patterns that were directly linked to the neurotoxic process. In particular, because early critical stages of METH-induced DA neurotoxicity take place within a well defined time frame $(<24 \mathrm{hr}$ after METH administration) (Ricaurte et al., 1982; Marek et al., 1990a), and because the toxic effects of METH on DA neurons can be completely blocked with DAT inhibitors (Ricaurte et al., 1984; Marek et al., 1990a,b; Pu et al., 1994, Callahan et al., 2001), we reasoned that by comparing mRNA expression patterns in the presence and absence of a DAT inhibitor (W IN35,428) within $24 \mathrm{hr}$ after METH administration, we might be able to identify a gene expression pattern ("signature") associated with early stages of METH-induced neurotoxicity (see below). Choice of the DAT inhibitor WIN35,428 was on the basis of findings from previous studies indicating that its DA neuroprotective effect is independent of effects on temperature (Callahan et al., 2001). The time course for analyses (3, 6, 12, and $24 \mathrm{hr}$ after METH administration) was selected on the basis of the fact that we sought to identify genes that played a role in the early phases of METH neurotoxicity: ideally, genes that were directly involved in the neurotoxic process (which is known to occur sometime within the first $24 \mathrm{hr}$ after METH administration). The decision to initially target microarray analyses to ventral midbrain, which contains the DA neuron cell bodies, was based on the reasonable (but yet to be validated) assumption that gene expression changes associated with METH neurotoxicity are likely to occur in the cell body compartment of DA neurons with axons that are damaged by METH. The fact that DA cell bodies are typically spared by METH therefore could make it possible to identify gene expression changes within DA neurons associated with the neurotoxic process. As alluded to above, we characterized gene expression profiles using recently developed DA and neuronal microarrays containing $\sim 1600$ genes (Barrett et al., 2001), reasoning that use of these arrays would increase the likelihood of identifying highly relevant gene products. Because METH-induced DA neurotoxicity is completely prevented by DAT blockers, including WIN35,428 (see Results), parallel gene profiles were determined with WIN35,428 (given alone or in combination with METH) at the various time points. This was done recognizing that when using WIN35,428, one is blocking not only METH-induced DA neurotoxicity but also METH-induced DA release (and all of the postsynaptic actions of DA), which may or may not be associated with the neurotoxic process. Although this approach has the potential to identify or include candidate genes that, although perhaps related to DA release, are not directly liked to METH-induced DA neurotoxicity, there is evidence that METH-induced DA release is linked to METH-induced DA neurotoxicity (O'Dell et al., 1991). For microarray studies, ventral midbrain tissues ( $n=12$ per group) were collected $3,6,12$, and $24 \mathrm{hr}$ after treatment with METH $(45 \mathrm{mg} / \mathrm{kg}$, s.c.), WIN35,428 $(12.5 \mathrm{mg} / \mathrm{kg}$, i.p., immediately before METH) plus METH, WIN35,428 alone, or saline.

WIN35,428 blockade of METH-induced DA neurotoxicity. Mice were treated with METH (45 mg/kg, s.c.), WIN35,428 (12.5 mg/kg, i.p.) alone, WIN35,428 (immediately before METH) plus METH, or saline at room temperature. Rectal temperatures were measured for $24 \mathrm{hr}$ after drug administration, and all mice were killed 1 week after treatment for measurement of brain biogenic amines, as below.

$D A$ and DOPAC determinations. Concentrations of DA and DOPAC in the mouse striatum were measured by means of HPLC coupled with electrochemical detection, as described previously (Ricaurte et al., 1992).

Measurement of tissue METH levels. Striatal METH concentrations 0.5 and $2 \mathrm{hr}$ after drug administration were measured using an RIA kit, as described previously (Callahan et al., 2001).

Synaptosomal preparation. Synaptosomes were prepared from striatal 
tissue at designated times after treatment with cycloheximide, actinomycin-D, or saline. Striatal tissue was placed in $20 \mathrm{vol}(\mathrm{w} / \mathrm{v})$ of 0.32 M sucrose, homogenized with a glass-Teflon pestle, and centrifuged at $2000 \times g$ for $10 \mathrm{~min}$. The synaptosome-rich supernatant was retained and stored on ice until use. Protein contents were assayed for quantitative comparisons (Lowry et al., 1951). The synaptosomal preparations were used for studies of DAT function after the in vivo administration of cycloheximide and actinomycin-D.

$\left[{ }^{3} H\right] D A$-uptake. Accumulation of $\left[{ }^{3} \mathrm{H}\right] \mathrm{DA}$-uptake by synaptosomes was measured using recently described methods (Kim et al., 2000).

$\left[{ }^{3} \mathrm{H}\right]$ WIN35,428 binding. $\left[{ }^{3} \mathrm{H}\right] \mathrm{WIN} 35,428$ binding assays were performed as described recently (Kim et al., 2000).

Dissection of ventral midbrain. The ventral midbrain containing the substantia nigra (pars compacta and pars reticulata) and ventral tegmental area was dissected free using the guidelines of Heffner et al. (1980), adapted to the mouse.

RNA isolation, probe labeling, and microarray hybridization. Total RNA was isolated from pooled ventral midbrain tissue of mice $(n=12$ per group), using RNAzol B as directed by the manufacturer. The quantity and quality of RNA were measured by spectrophotometry and electrophoresis on denaturing agarose gel. Radiolabeled cDNA probes were synthesized from $10 \mu \mathrm{g}$ total RNA in the presence of dATP, dTTP, dGTP, ${ }^{33} \mathrm{P}$ dCTP, polyT, Superscript II RNase $\mathrm{H}^{-}$Reverse Transcriptase, and RNaseOUT Recombinant Inhibitor, as described previously (Whitney et al., 1999). The probes were purified using a SP-30 column and quantified using a liquid scintillation counter. Array membranes were prehybridized for $4 \mathrm{hr}$ at $60^{\circ} \mathrm{C}$ in $4 \mathrm{ml}$ Microhyb hybridization buffer, $100 \mu \mathrm{g}$ Human Cot-1 DNA, and $40 \mu \mathrm{g}$ polyA in $50 \mathrm{ml}$ Falcon tubes. Heat-denatured probe was hybridized overnight at $60^{\circ} \mathrm{C}$ in a rotating hybridization oven. Membranes were washed at room temperature with $2 \times \mathrm{SSC} / 0.1 \% \mathrm{SDS}$ twice for $10 \mathrm{~min}$ and at $60^{\circ} \mathrm{C}$ with $0.5 \times$ $\mathrm{SSC} / 0.1 \% \mathrm{SDS}$ twice for $10 \mathrm{~min}$. The membranes were then exposed to bleached phosphor screens for 2-3 d. Image acquisition and quantification were performed using a phosphorimager STORM 860 system and ImageQuant software (Amersham Biosciences). Replicates were performed at least one time using tissue from different animals to prepare RNA for labeling for the 12 and $24 \mathrm{hr}$ time-point study on the DA microarray and the same sample of RNA for labeling for the rest of the time-point studies on DA and neuronal microarrays. Each membrane contained duplicate copies of the gene. Coefficient of variation (CV) values were calculated to determine the reliability between duplicate gene sets within an array.

Analysis of microarray data. Overall differences in gene expression between samples were calculated by a global normalization method based on the total intensity of counts for each membrane. A normalization factor was determined by dividing the average total intensity by the true total intensity. Each spot was multiplied by its appropriate normalization factor and differences were calculated as ratios (fold changes) from the normalized values. Background levels were determined to be uniform across each membrane and were not subtracted from the calculations. Data were analyzed using MS Excel and SpotFire Pro 4 software (Spotfire Inc., Cambridge, MA). Only those membranes with highly consistent results between copies of the gene set, as indicated by a CV value $<0.2$, were used.

Northern blot analysis. These studies were performed to confirm the reliability of the microarray data and to extend the findings with cytochrome $c$ oxidase subunit 1 (COX1). DNA probes for COX1, heat shock protein 84 (HSP84), and reduced nicotinamide adenine dinucleotide (NADH) ubiquinone oxidoreductase chain 4 (NADH4) were derived from the same set of PCR products as those used to generate the DNA microarray. HSP84 was selected for these studies because Kuperman and colleagues (1997) showed previously that a related heat shock protein, HSP72, is upregulated $12 \mathrm{hr}$ after the METH-induced neurotoxicity, and because the array results (see Table 2) suggested that HSP84 was increased, although the increase was less than twofold (1.6-fold at $12 \mathrm{hr}$ after METH administration). Therefore, we thought it would be of interest to further study HSP84 to determine whether seemingly positive data in the array could be corroborated by Northern blot analysis. NADH4 was selected because we observed virtually no change 12 and 24 hr after METH administration in the array studies. Accordingly, we sought to confirm the negative results in microarray studies with Northern blotting analyses. PCR products were partially sequenced to confirm correct gene identification. $\beta$-actin was used as an internal control to calibrate the loading amount of total RNA. Ventral midbrain tissues $(n=$ 12 per group) were collected $3,6,12$, and $24 \mathrm{hr}$ after being treated with
METH (45 mg/kg, s.c.), WIN35,428 (12.5 mg/kg, i.p., immediately before METH) plus METH, WIN35,428 alone, or saline, as in the microarray study. Ventral midbrain tissues of mice treated with METH $(45 \mathrm{mg} / \mathrm{kg}$, s.c.) or saline in a cold room, a condition previously known to block neurotoxicity (Xie et al., 2000), were also collected ( $n=12$ per group) 12 and $24 \mathrm{hr}$ after the treatment. Probes were radiolabeled using a random primer labeling system in the presence of ${ }^{33} \mathrm{P}$ dCTP. Extracted total RNA (10 $\mu \mathrm{g}$ per lane) was used for Northern analysis as described previously (Xie et al., 1999). The hybridization and washing conditions were similar to those used in microarray experiments. The blots were scanned with a phosphorimager and semiquantitatively analyzed using ImageQuant, as mentioned above. The results were expressed as a ratio of target gene (i.e., COX1, NADH4, HSP84) counts in treated (METH, or METH plus WIN35,428, or WIN35,428) mice/target gene counts in control (saline) mice after correction for RNA loading using $\beta$-actin.

In vitro transcription of $c R N A$ probes of $C O X 1$ for in situ hybridization. The antisense and sense cRNA probes of COX1 were transcribed in vitro after PCR. PCR primers were targeted to the open reading frame of the mice COX1 gene (Bibb et al., 1981), bases 5380 through 5799, which is also part of the sequenced region of the COX1 gene. Blast search in National Center for Biotechnology Information showed very low homology of this region with other genes. Each primer consisted of specific bases for the targeted COX1 sequence and the promoter site of either SP6 or T7 RNA polymerase. The upstream primer, GGGATTTAGGTGACACTATAGAACTATCTACTATTCGGAGCCTGA, contained 23 bases of SP6 RNA polymerase promoter region. The downstream primer, CTGTAATACGACTCACTATAGGGTAGATGACACTCCAGCTAAATG, contained 23 bases of T7 RNA polymerase promoter region. PCR was performed using the PCR kit, the above primers (25 $\mu \mathrm{M})$ and recombinant plasmids containing the COX1 DNA $(0.5 \mu \mathrm{g})$. The PCR conditions were as the follows: $94^{\circ} \mathrm{C}$ for $3 \mathrm{~min}$ followed by $94^{\circ} \mathrm{C}$ for $40 \mathrm{sec}, 68^{\circ} \mathrm{C}$ for $40 \mathrm{sec}, 72^{\circ} \mathrm{C}$ for $1 \mathrm{~min}$, for $32 \mathrm{cycles}$, and a final extension time of $10 \mathrm{~min}$ at $72^{\circ} \mathrm{C}$. The PCR products were then used for in vitro transcription using the mixture of ATP, CTP, GTP, and fluorescein-UTP from the in situ detection kit in combination with the transcription kit, as directed by the manufacturer. T7 RNA polymerase transcripted the antisense cRNA probe and the SP6 RNA polymerase transcripted the sense cRNA probe (control) in a $20 \mu \mathrm{l}$ reaction volume incubated for $2 \mathrm{hr}$ at $37^{\circ} \mathrm{C}$. An extra reaction without the presence of any RNA polymerase was used as an additional negative control (zero probe). The probes were used immediately or stored at $-70^{\circ} \mathrm{C}<2 \mathrm{~d}$ before use.

In situ hybridization. These studies were performed as described previously (Chesselet et al., 1987; Kerner et al., 1998), with minor modification. Animals were decapitated, and the brains were removed and quickly frozen on dry ice and stored at $-70^{\circ} \mathrm{C}$ until processed further. Sections of ventral midbrain were cut at $12 \mu \mathrm{m}$ thickness using a cryostat. The slides were fixed in $3 \%$ paraformaldehyde in $\mathrm{PBS}, \mathrm{pH} 7.4$, for $7 \mathrm{~min}$ and washed in three changes of PBS (5 min each) treated with $0.1 \%$ DEPC ( 5 min each). The sections were then pretreated with $0.25 \%$ acetic anhydride in $0.1 \mathrm{M}$ triethanolamine $/ 0.9 \% \mathrm{NaCl}, \mathrm{pH} 8.0$, for $10 \mathrm{~min}$ at room temperature and rinsed in PBS $(5 \mathrm{~min})$ once. The sections were dehydrated through $70,85,95$, and $100 \%$ ethanol ( 2 min each), delipidated with chloroform for $10 \mathrm{~min}$, washed with 100 and $95 \%$ ethanol (2 min each), and dried. The antisense cRNA, sense cRNA, and zero probe were dissolved in the hybridization buffer ( $\sim 600 \mathrm{ng} / \mathrm{ml}$ for the probes), denatured at $70^{\circ} \mathrm{C}$ for $15 \mathrm{~min}$, chilled on ice for $2 \mathrm{~min}$, and hybridized with the dried sections in a moist chamber at $60^{\circ} \mathrm{C}$ overnight. The total volume of hybridization buffer was $80 \mu \mathrm{l}$ per section. The slides were then washed with $1 \times \mathrm{SSC} / 0.1 \% \mathrm{SDS}$ at room temperature twice for $10 \mathrm{~min}$ and with $0.2 \times \mathrm{SSC} / 0.1 \% \mathrm{SDS}$ preheated to $55^{\circ} \mathrm{C}$ three times for $10 \mathrm{~min}$. After they were washed at $2 \times \mathrm{SSC}$ for $2 \mathrm{~min}$, hybridization products were digested in prewarmed $10 \mu \mathrm{g} / \mathrm{ml} \mathrm{RNase} \mathrm{A} \mathrm{with} 2 \times \mathrm{SSC}$ at $37^{\circ} \mathrm{C}$ for 20 min. A color RNA kit using nitroblue tetrazolium and 5-bromo-4-chloro3 -indolyphosphate $p$-toluidine salt as chemogen was then used to detect the hybridization signals, as directed by the manufacturer. After the color development, quantification of cell bodies for the relative optical density of the hybridization signal intensity in the ventral midbrain was performed with the micro-computer image device image analysis system, as described previously (Hatzidimitriou et al., 1999).

Statistical analysis. Neurochemical data and microarray data were analyzed by one-way ANOVA, followed by Duncan's multiple range post hoc comparisons, where appropriate. Linear regression was used to explore the relation between data from microarrays and Northern anal- 
yses. In situ hybridization data were analyzed by independent $t$ test. Results were considered significant when $p$ values were $<0.05$, using a two-tailed test. Data analysis was performed using the Statistical Program for the Social Sciences (SPSS for Windows, Release 6).

\section{RESULTS}

\section{Cycloheximide}

As noted above, Finnegan and Karler (1992) previously reported that cycloheximide could block METH neurotoxicity. However, because many agents that protect against METH-induced DA neurotoxicity do so by inducing hypothermia (Bowyer et al., 1992, 1994; Miller and O'Callaghan, 1994; Albers and Sonsalla, 1995; Ali et al., 1996), it was necessary to eliminate drug-induced hypothermia as a possible confound. This was accomplished by performing drug treatments in a warm environment to prevent drug-induced hypothermia. Under these conditions, when given alone, METH produced a $\sim 70 \%$ reduction in DA axonal markers 1 week later (Fig. 1a,b), with no significant changes in 5-HT axonal markers (data not shown). Cycloheximide, by itself, did not produce any long-term effects on brain DA axonal markers. However, when given before METH, cycloheximide completely blocked the toxic effect of METH on DA neurons (Fig. 1a,b), independent of effects on core temperature (Fig. 1c).

Another way cycloheximide could afford neuroprotection is by interfering with DAT function. To rule out this possibility, DAT function and $\left[{ }^{3} \mathrm{H}\right]$ WIN35,428 binding were measured in striatal tissues prepared from mice treated with cycloheximide 1, 1.5, and $2.5 \mathrm{hr}$ previously. These times correspond to the time points of $0.5,1$, and $2 \mathrm{hr}$ after METH administration (because of the $0.5 \mathrm{hr}$ stagger in drug administration). Cycloheximide did not interfere with either $\left[{ }^{3} \mathrm{H}\right]$ DA uptake or $\left[{ }^{3} \mathrm{H}\right]$ W IN35,428 binding at any of the times examined (data not shown).

Because cycloheximide could also protect against the neurotoxic effects of METH by altering its biodisposition, we next examined the effect of cycloheximide on striatal METH levels. Concentrations of METH in the striatum were measured 0.5 and $2 \mathrm{hr}$ after METH administration. Pretreatment with cycloheximide did not significantly alter striatal METH levels (at $0.5 \mathrm{hr}$, METH concentrations after METH alone and cycloheximide plus METH treatment were $1438 \pm 39 \mathrm{ng} / \mathrm{mg}$ tissue and $1370 \pm$ $52 \mathrm{ng} / \mathrm{mg}$ tissue, respectively; at $2 \mathrm{hr}$, METH concentrations after METH alone and cycloheximide plus METH treatments were $858 \pm 89 \mathrm{ng} / \mathrm{mg}$ tissue and $918 \pm 12 \mathrm{ng} / \mathrm{mg}$ tissue, respectively).

\section{Actinomycin-D}

To test the hypothesis that transcription of certain genes soon after METH administration might be essential for the expression of METH-induced DA neurotoxicity, we examined the effect of the mRNA synthesis inhibitor, actinomycin-D. When given alone, METH produced a $\sim 70 \%$ reduction in DA axonal markers (DA and DOPAC) 1 week later (Fig. 2a,b). Actinomycin-D, given alone, did not produce any long-term effects on brain DA axonal markers. However, when given before METH, actinomycin-D completely blocked the toxic effect of METH on DA neurons (Fig. 2a,b). As shown in Figure 2, animals treated with METH alone or in combination with actinomycin-D had virtually identical core temperature curves (Fig. 2c), indicating that the neuroprotective effect of actinomycin was not related to thermoregulatory influences.

Possible effects of actinomycin-D on DAT function and METH metabolism were also investigated. $\left[{ }^{3} \mathrm{H}\right]$ DA uptake and $\left[{ }^{3} \mathrm{H}\right]$ WIN35,428 binding were measured $2.5,3$, and $4 \mathrm{hr}$ after the administration of actinomycin-D, which corresponded to $0.5,1$,
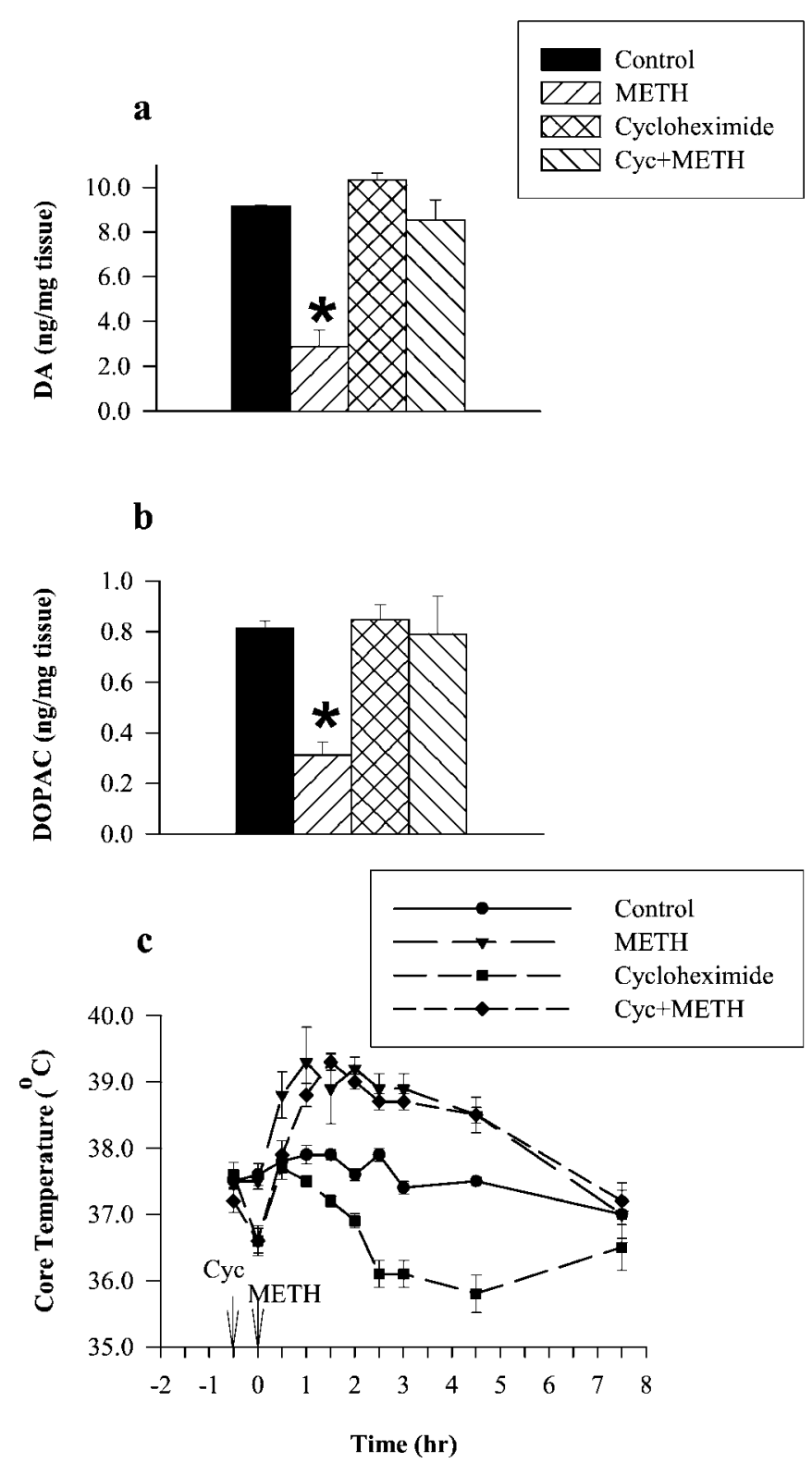

Figure 1. Effect of cycloheximide and METH, alone and in combination, on striatal DA $(a)$, DOPAC $(b)$, and core temperature $(c)$. Mice received either vehicle (saline), METH (45 mg/kg, s.c.), cycloheximide $(150 \mathrm{mg} /$ $\mathrm{kg}$, s.c.), or METH (45 mg/kg, s.c.) plus cycloheximide $(150 \mathrm{mg} / \mathrm{kg}$, s.c., $0.5 \mathrm{hr}$ before METH). Core temperature was measured during drug treatment, as described in Materials and Methods. For DA and DOPAC determinations, mice were killed 1 week after drug treatment. Results shown represent the mean \pm SEM for each group ( $n=5$ per group). * designates significant difference from control $(p<0.05)$.

and $2 \mathrm{hr}$ after METH (because of the $2 \mathrm{hr}$ stagger in administration of the two drugs) (Fig. 3). Actinomycin-D did not decrease DA transporter function at $2.5 \mathrm{hr}$, which is equivalent to $0.5 \mathrm{hr}$ after METH, when peak levels of METH are achieved. However, at 3 and $4 \mathrm{hr}$, actinomycin-D did cause a slight reduction in DA uptake and $\left[{ }^{3} \mathrm{H}\right]$ WIN35,428 binding, but these effects were small $(8-28 \%)$ and transient, as evidenced by the fact that inhibition at $4 \mathrm{hr}(8 \%)$ was less than at $3 \mathrm{hr}(20-28 \%)$ (Fig. 3).

Pretreatment with actinomycin-D $2 \mathrm{hr}$ before METH did not significantly alter brain levels of METH (data not shown; results were similar to those described above for cycloheximide), miti- 


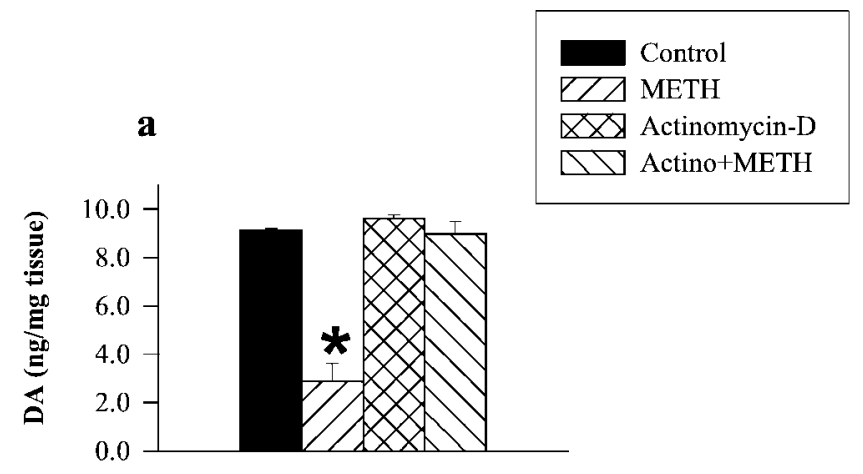

b
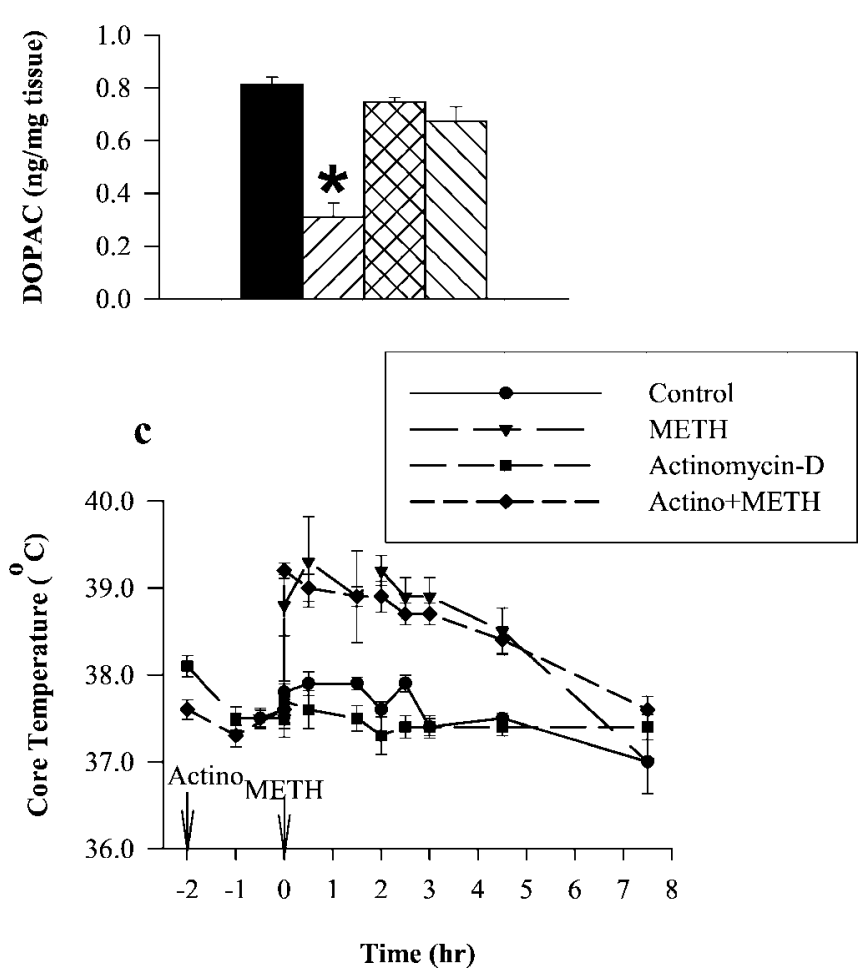

Figure 2. Effect of actinomycin-D and METH, alone or in combination, on striatal DA $(a)$, DOPAC $(b)$, and core temperature $(c)$. Mice received vehicle (saline), METH ( $45 \mathrm{mg} / \mathrm{kg}$, s.c.), actinomycin-D ( $0.5 \mathrm{mg} / \mathrm{kg}$, i.p.), or METH $(45 \mathrm{mg} / \mathrm{kg}$, s.c.) plus cycloheximide $(0.5 \mathrm{mg} / \mathrm{kg}$, i.p., $2 \mathrm{hr}$ before $\mathrm{METH})$. Core temperature was measured during drug treatment, as described in Materials and Methods. For DA and DOPAC determinations, mice were killed 1 week after drug treatment. Results shown represent the mean \pm SEM for each group $\left(n=5\right.$ per group). ${ }^{*}$ designates significant difference from control $(p<0.05)$.

gating against the possibility that the neuroprotection of actinomycin was attributable to a lowering of METH brain levels.

\section{Microarray findings}

To further evaluate the role of gene expression in METHinduced DA neurotoxicity, we next used microarray technology in combination with an experimental approach designed to facilitate recognition of relevant changes in gene expression (see Microarray methods). In essence, by subtracting the set of genes expressed when METH is given in combination with the DAT inhibitor, WIN35,428 [which affords complete neuroprotection against METH toxicity (Fig. 4)], from the larger set of genes

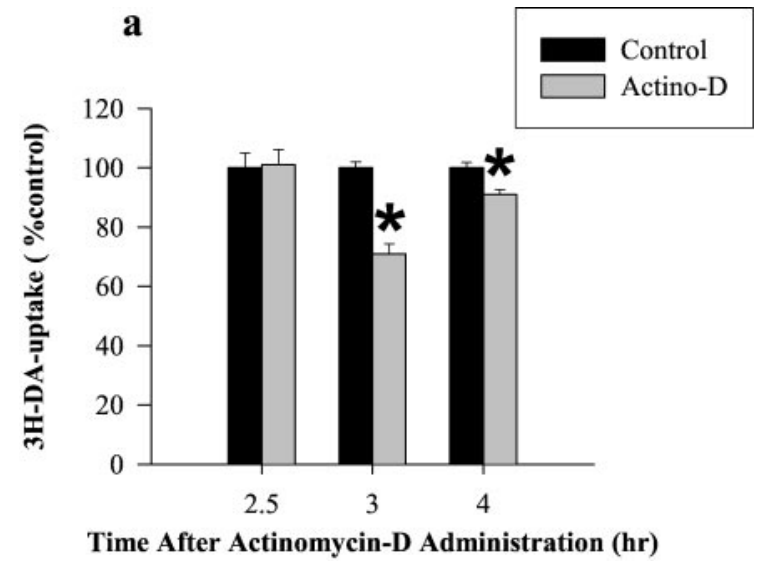

b

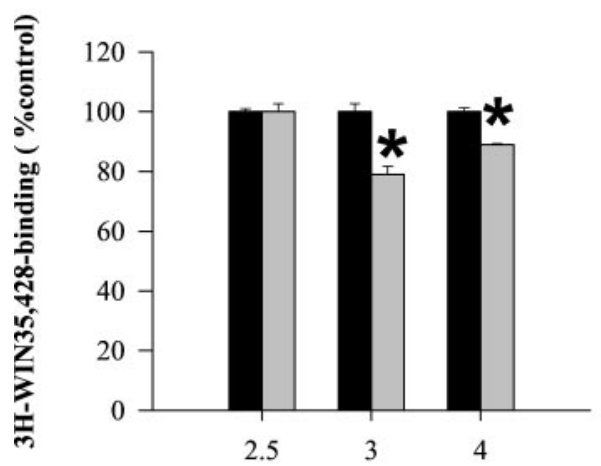

Time After Actinomycin-D Administration (hr)

Figure 3. Effect of actinomycin-D on $\left[{ }^{3} \mathrm{H}\right]$ DA uptake $(a)$ and $\left[{ }^{3} \mathrm{H}\right]$ WIN35,428 binding $(b)$. Uptake and binding studies were performed as described in Materials and Methods. Results shown represent mean \pm SEM for each group $(n=3$ per group). * designates significant difference from control $(p<0.05)$.

expressed when METH is given alone, a number of genes associated with the neurotoxic process were identified (Fig. 5, Table 1). Of a total of $\sim 1600$ genes screened on the DA and neuronal chips, only those genes differentially upregulated or downregulated by at least a factor of 2 are presented (Fig. 5, Table 1). Three hours after METH, genes with expression that was differentially altered included those encoding for adenylyl cyclase III, the solute carrier family 10 (sodium/bile acid cotransporter) member 1 (SLC10A1), and the solute carrier family 9 (sodium/hydrogen exchanger) isoform 3 regulatory 1 (SLC9A3R1). In each of these cases, gene expression was downregulated. At $6 \mathrm{hr}$, no genes were differentially expressed (i.e., all genes expressed after METH were also expressed after METH plus WIN35,428). By contrast, at $12 \mathrm{hr}$, the expression of several genes was differentially altered. These included COX1, NADH2, and $N$-myc downstreamregulated gene 3 (NDR3). At $24 \mathrm{hr}, \mathrm{COX} 1$, tau microtubuleassociated protein (Tau), phosphoglycerate mutase B, and NDR3 were differentially expressed, with COX1 still showing upregulation and the remaining genes showing downregulation.

\section{Northern blot analyses}

To confirm and extend the array data, Northern blot analyses of the COX1, HSP84, and NADH4 gene products were performed under the various experimental conditions (METH with and without WIN35,428) at 12 and 24 hr (Fig. 6, Table 2). Northern blot analyses confirmed the upregulation of COX1 mRNA ex- 

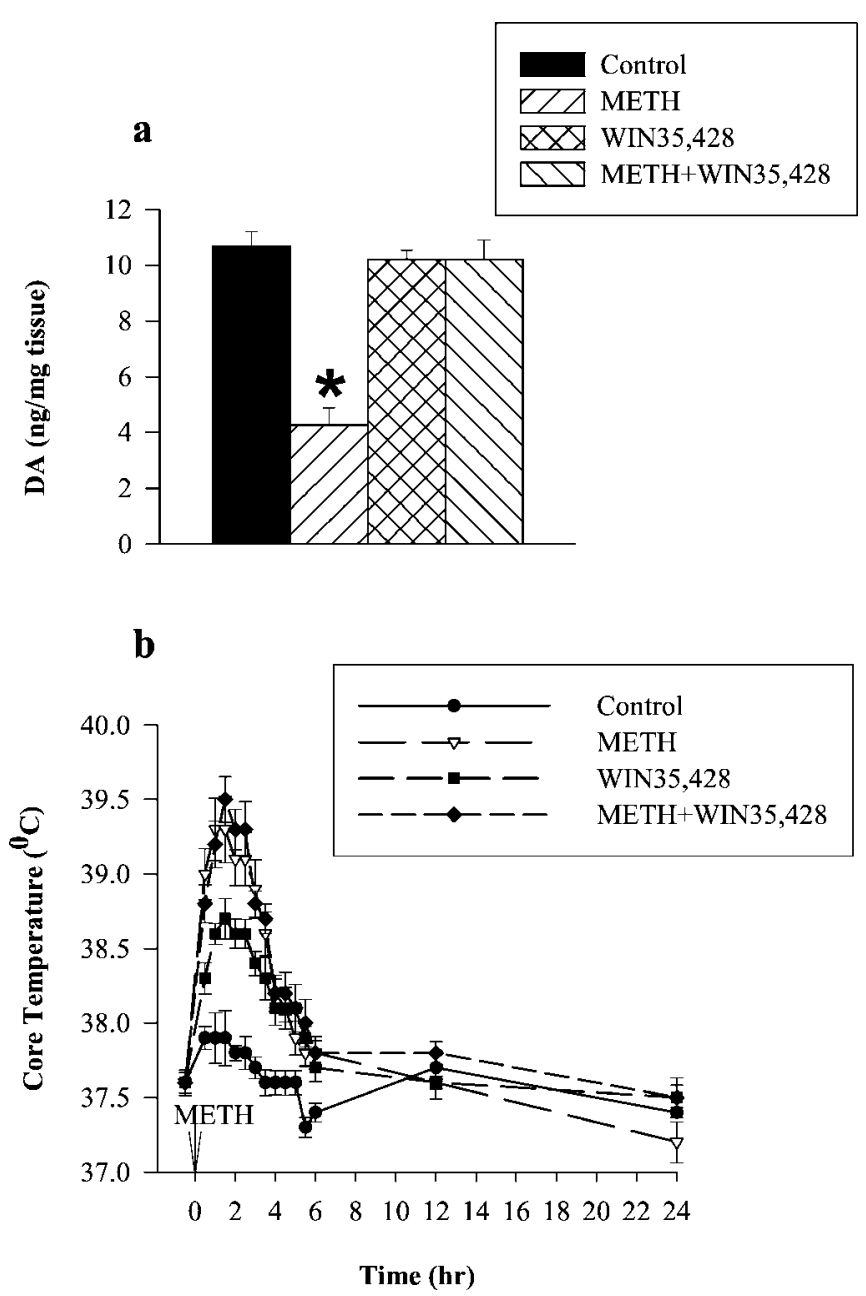

Figure 4. WIN35,428 blockade of METH-induced DA neurotoxicity. Mice were treated with METH (45 mg/kg, s.c.), WIN35,428 $(12.5 \mathrm{mg} / \mathrm{kg}$, i.p.), WIN35,428 (12.5 mg/kg, i.p., immediately before METH) plus METH (45 mg/kg, s.c.), or saline at room temperature. Rectal temperatures were measured during drug treatment, and mice were killed 1 week later for measurement of striatal DA and DOPAC levels, as described in Materials and Methods. Results shown represent the mean \pm SEM for each group ( $n=6$ per group).

pression after METH (up 2.5-fold at $12 \mathrm{hr}$ and 3.0-fold at $24 \mathrm{hr}$ ) (Table 2), which were primarily blocked by WIN35,428 (only up 1.2-fold at $12 \mathrm{hr}$ and 1.3-fold at $24 \mathrm{hr}$ ) (Table 2), which afforded complete neuroprotection (Fig. 4). The correlation between data from microarray and Northern blotting analyses was $r=0.90$ $(p<0.01)$.

\section{In situ hybridization}

To define the cellular localization of the observed increase in COX1 transcription in the substantia nigra in the setting of METH neurotoxicity, we next performed in situ hybridization studies. Mice for these studies were treated with METH (45 $\mathrm{mg} / \mathrm{kg}$, s.c.) or saline and killed $24 \mathrm{hr}$ later, because it was at this time point that COX1 mRNA levels were highest. In sections hybridized with the antisense cRNA COX1 probe, a twofold increase in COX1 mRNA was found in nerve cells located in the pars reticulata of the substantia nigra of mice previously treated with METH compared with those treated with saline (Fig. 7). Virtually no positive signal was found in sections hybridized with sense probe, nor was any increase in signal observed in sections hybridized without any probe.

\section{Effect of temperature}

To further explore the role of increased COX1 expression in the context of METH-induced DA neurotoxicity, the effect of preventing METH-induced DA neurotoxicity by means of inducing hypothermia was evaluated. Mice were treated with METH in a cold room $\left(6 \pm 1^{\circ} \mathrm{C}\right)$ and maintained at this ambient temperature for an additional $6 \mathrm{hr}$ after METH treatment. Twelve and $24 \mathrm{hr}$ later, the mice were killed for Northern blot analyses of the COX1 mRNA level. Under these experimental conditions, which completely prevent METH-induced DA neurotoxicity (Xie et al., 2000), there was no increase in COX 1 transcription at either 12 or $24 \mathrm{hr}$ (data not shown), further suggesting that increased COX1 expression and METH-induced DA neurotoxicity are closely linked phenomena.

\section{DISCUSSION}

The results of the present studies indicate that gene expression is involved in METH-induced brain DA neurotoxicity. Using a combination of microarray and targeted pharmacological and physiological strategies, we have identified several genes the expression of which is associated with METH-induced DA neuronal injury, including COX1 in the ventral midbrain. To our knowledge, these are the first data to implicate specific gene products in the toxic effect of METH on nigrostriatal DA neurons.

The present findings confirm and extend the earlier report by Finnegan and Karler (1992) indicating that the protein synthesis inhibitor, cycloheximide, protects against METH-induced DA neurotoxicity. Since that report originally appeared, it has become clear that many of the drugs that protect against $\mathrm{METH}-$ induced DA neurotoxicity do so via indirect drug effects on temperature, DAT function, or brain METH levels. However, by demonstrating that the neuroprotective effects of cycloheximide in METH-treated animals are not confounded by drug effects on any of these parameters, the present results lend further support to the idea that certain gene products are required for the expression of METH neurotoxicity.

To more directly evaluate the role of gene expression in METH neurotoxicity, the present study examined the effect of the transcription inhibitor, actinomycin-D. Results indicate that actinomycin-D, like cycloheximide, affords complete neuroprotection, and that this effect, like the neuroprotective effect of cycloheximide, is primarily independent of drug effects on core temperature, DAT function, or METH brain levels. Although actinomycin-D partially decreased DAT function at certain time points, these effects were modest (8-28\%) and transient (less at 4 $\mathrm{hr}$ than $3 \mathrm{hr}$ ), making it likely that the major fraction of the neuroprotective effect of antyinomcin-D is related to its inhibitory action on gene transcription. Taken together, results from studies with cycloheximide and actinomycin-D provided a theoretical basis for further evaluating the role of gene expression in METH-induced DA neurotoxicity.

By using "subtractive" microarray approaches (i.e., by subtracting or eliminating consideration of those genes with expression that also changes when METH is given in combination with WIN35,428, which completely blocks METH-induced DA neurotoxicity) (Fig. 4), several genes linked to the neurotoxic process have been identified (Table 1). These include genes with products that are involved in energy metabolism (COX1, NADH2, and 
Figure 5. Representative scatter plots demonstrating the strategy used to identify genes specifically involved in METH-induced DA neurotoxicity. Neuronal array hybridization data $3 \mathrm{hr}$ after various treatments are shown. Methods are as described in Materials and Methods. Each panel contains 1100 genes. The red dots represent genes with expressions that have been either upregulated or downregulated by at least a factor of 2 compared with control. Listed in the $y$-axis are the log-transformed intensity data for the genes expressed after being treated with METH alone, METH plus WIN35,428, or WIN35,428 alone. Listed in the $x$-axis are the log-transformed intensity data for genes expressed after saline treatment as control. There are 11 serial density reads ranging from 2000 to 20,000 on the $x$ - and $y$-axis; only the first and last reads on the figures are labeled because of the limit in space. Only those genes upregulated or downregulated by at least a factor of 2 in the METH group but not in the other groups (METH plus WIN35,428 and WIN35,428 alone) were viewed as being specifically involved in METH neurotoxicity.

\begin{tabular}{|c|c|c|c|c|c|}
\hline Time & Genes & Function & $\mathrm{METH} /$ control & METH + WIN/control & WIN/control \\
\hline \multirow[t]{3}{*}{$3 \mathrm{hr}$} & Adenylyl cyclase III & Signal transduction & $\downarrow 2.22(2.04-2.50)^{a}$ & $\downarrow 1.37(1.23-1.54)$ & $\downarrow 1.08(1.02-1.14)$ \\
\hline & SLC10A1 & Ion transportation & $\downarrow 2.33(2.13-2.63)^{a}$ & $\downarrow 1.43(1.30-1.56)$ & $\downarrow 1.11(1.10-1.12)$ \\
\hline & SLC9A3R1 & Ion transportation & $\downarrow 2.13(2.00-2.27)^{a}$ & $\downarrow 1.45(1.35-1.55)$ & $\downarrow 1.08(1.04-1.11)$ \\
\hline \multirow[t]{3}{*}{$12 \mathrm{hr}$} & COX1 & ATP generation (major player) & $\uparrow 2.40(2.15-2.70)^{b}$ & $\uparrow 1.68(1.52-1.78)$ & $\uparrow 1.47(1.36-1.58)$ \\
\hline & NADH2 & ATP generation & $\downarrow 2.13(2.04-2.22)^{b}$ & $\downarrow 1.27(1.27-1.28)$ & $\downarrow 1.02(1.01-1.03)$ \\
\hline & NDR3 & Cell differentiation & $\downarrow 2.02(1.96-2.08)^{b}$ & $\downarrow 1.33(1.30-1.37)$ & $\downarrow 1.09(1.05-1.14)$ \\
\hline \multirow[t]{4}{*}{$24 \mathrm{hr}$} & COXI & ATP generation (major player) & $\uparrow 2.62(2.45-3.01)^{b}$ & $\uparrow 1.35(1.30-1.40)$ & $\uparrow 1.90(1.78-1.98)$ \\
\hline & Phosphoglycerate mutase B & Glycolysis for ATP & $\downarrow 2.17(2.08-2.27)^{a}$ & $\uparrow 1.06(1.02-1.10)$ & $\downarrow 1.33(1.25-1.43)$ \\
\hline & $\mathrm{Tau}$ & Neurodegeneration & $\downarrow 2.17(2.04-2.38)^{a}$ & $\downarrow 1.10(1.07-1.12)$ & $\downarrow 1.22(1.20-1.24)$ \\
\hline & NDR3 & Cell differentiation & $\downarrow 2.00(1.90-2.10)^{b}$ & $\downarrow 1.12(1.09-1.22)$ & $\downarrow 1.33(1.25-1.41)$ \\
\hline
\end{tabular}

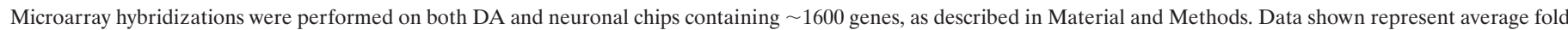

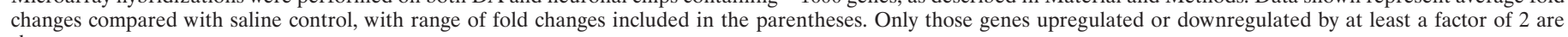
shown.

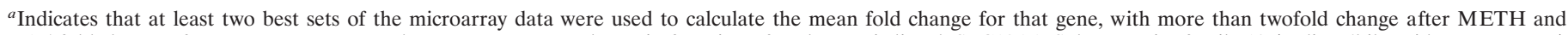

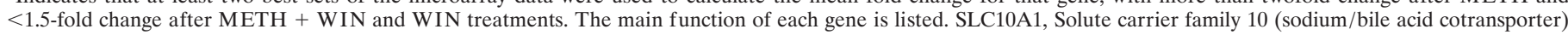

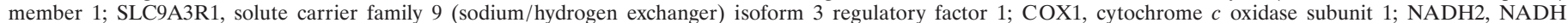
ubiquinone oxidoreductase chain 2; NDR3, $N$-myc downstream regulated gene 3; Tau, tau microtubule-associated protein.

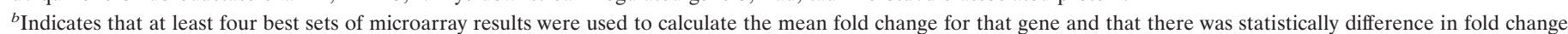
between METH and METH + WIN35,428 or WIN35,428 alone, using one-way ANOVA (Duncan test) at a level of $p<0.05$.

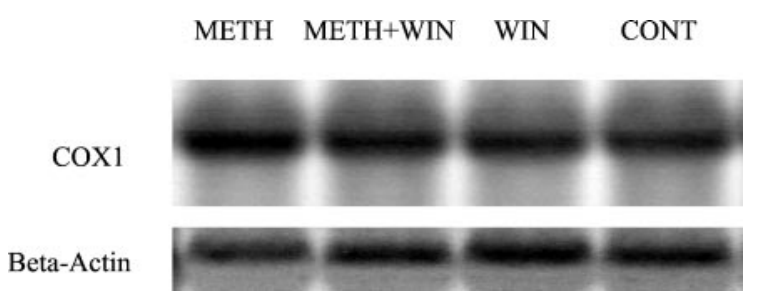

Figure 6. Representative image for Northern blot analysis of COX1 mRNA levels $12 \mathrm{hr}$ after various treatments. The method was as described under Materials and Methods. $\beta$-actin cDNA probe was used as internal control. Note increase in COX1 mRNA level after METH.

phosphoglycerate mutase B), ion regulation (members of sodium/ bile acid cotransporter SLC10A1 and sodium/hydrogen exchanger SLC9A3R1), signal transduction (adenylyl cyclase III), and cell differentiation and degeneration (NDR3 and Tau). Given the implied or suspected role of some of these processes in METH neurotoxicity, differential expression of these genes in the context of METH neurotoxicity is of interest.
Of the various genes with expression that changed differentially in the setting of METH-induced DA neural injury, we elected to further explore the increase in COX1 because of reports implicating energy metabolism in METH neurotoxicity (Huang et al., 1997; Stephans et al., 1998; Burrows et al., 2000a) and because of reports that the DA neurotoxic effects of 1-methyl-4-phenyltetrahydropyridine (MPTP) and 6-hydroxydopamine (6-OHDA) are also associated with changes in COX activity (see below). To this end, Northern blotting studies were performed, followed by in situ hybridization studies. Northern analyses showed that COX1 expression was indeed increased and that the increase occurred only in mice treated with METH alone (not in mice treated with METH plus W IN35,428). Subsequent in situ hybridization studies confirmed and extended the microarray and Northern findings by showing that increased COX1 expression occurred in neurons located in the pars reticulata of the substantia nigra, in a region that corresponds almost precisely with the known location of GABA-containing neurons (GonzálezHernández and Rodríguez, 2000). Although these results further and directly implicate COX1 in METH neurotoxicity, they are 
Table 2. Confirmation of the microarray-derived COX1, HSP84, and NADH4 mRNA levels by Northern blot analyses

\begin{tabular}{|c|c|c|c|c|c|c|c|}
\hline \multirow[b]{2}{*}{ Time } & \multirow[b]{2}{*}{ Genes } & \multicolumn{2}{|c|}{$\mathrm{METH} /$ control } & \multicolumn{2}{|c|}{ METH + WIN/control } & \multicolumn{2}{|c|}{ WIN/control } \\
\hline & & Array & Northern & Array & Northern & Array & Northern \\
\hline \multirow[t]{3}{*}{$12 \mathrm{hr}$} & COX1 & $\uparrow 2.40$ & $\uparrow 2.50$ & $\uparrow 1.68$ & $\uparrow 1.20$ & $\uparrow 1.47$ & $\uparrow 1.01$ \\
\hline & HSP84 & $\uparrow 1.65$ & $\uparrow 1.80$ & $\uparrow 1.10$ & $\uparrow 1.03$ & $\uparrow 1.04$ & $\uparrow 1.20$ \\
\hline & NADH4 & $\downarrow 1.43$ & $\downarrow 1.11$ & $\downarrow 1.18$ & $\downarrow 1.11$ & $\downarrow 1.20$ & $\downarrow 1.20$ \\
\hline \multirow[t]{3}{*}{$24 \mathrm{hr}$} & COX1 & $\uparrow 2.62$ & $\uparrow 3.00$ & $\uparrow 1.35$ & $\uparrow 1.30$ & $\uparrow 1.90$ & $\uparrow 1.30$ \\
\hline & HSP84 & $\uparrow 1.10$ & $\uparrow 1.03$ & $\uparrow 1.01$ & $\uparrow 1.02$ & $\uparrow 1.01$ & $\uparrow 1.03$ \\
\hline & NADH4 & $\downarrow 1.25$ & $\downarrow 1.10$ & $\uparrow 1.10$ & $\uparrow 1.10$ & $\downarrow 1.16$ & $\downarrow 1.10$ \\
\hline
\end{tabular}

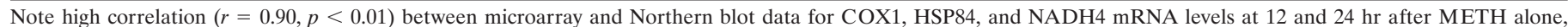

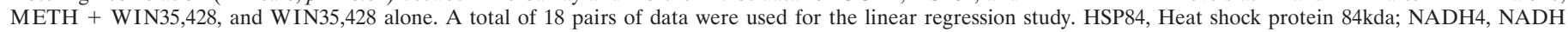
ubiquinone oxidoreductase chain 4 .

not sufficient to determine whether $\mathrm{COX} 1$ is related to the mechanisms of toxicity or a direct consequence of toxicity. COX1 expression, although increasing 12 and $24 \mathrm{hr}$ after METH, is not prominent at earlier time points ( 3 and $6 \mathrm{hr}$ ). Also, as mentioned above, in situ hybridization studies indicate that although the increase in COX1 expression takes place in the substantia nigra, it occurs in the pars reticulata, in a region where GABA, rather than DA, cell bodies are located (González-Hernández and Rodríguez, 2000). Nevertheless, when we tested the effects of METH given at low ambient temperature, which induces hypothermia and prevents METH-induced DA neurotoxicity (Ali et al., 1995; Xie et al., 2000), no increase in COX1 expression was observed, further attesting to the close link between METHinduced DA neurotoxicity and increased COX1 expression. Clearly, to completely delineate the role of COX1 in METH neurotoxicity, additional studies will be necessary. However, regardless of whether COX1 is involved in the fundamental mechanism of METH neurotoxicity or is a direct consequence of DA neuronal injury, to our knowledge it is one of the first reported changes in gene expression linked to the neurotoxic process.

Interestingly, in addition to a potential role in METH-induced DA neurotoxicity, alterations in COX activity have been reported after lesions induced by several classic neurotoxins, including MPTP, 6-OHDA, and quinolinic acid. For example, COX activity increases in the substantia nigra pars reticulata $20 \mathrm{~d}$ after MPTP lesions, with no changes at earlier times (Bezard et al., 2000). Conversely, using similar methods, rats receiving lesions in the striatum with the excitotoxin, quinolinic acid, were noted to have highly significant reductions in COX activity in several basal ganglia structures (including striatum but not substantia nigra pars compacta or pars reticulata) 1 week after injury, whereas rats lesioned with intrastriatal 6-OHDA did not show any changes in COX activity in any of the above regions (Levivier and Donaldson, 2000). Notably, although intrastriatal injections of 6-OHDA did not alter total COX activity in the substantia nigra, 6-OHDA lesions produced significant increases in COX1 mRNA in the subthalamic nucleus (Vila et al., 2000) and zona incerta (Périer et al., 2000), beginning $24 \mathrm{hr}$ after the lesion. Obviously, when interpreting these complex, seemingly contradictory data, the timing, anatomy, and nature of COX activity assessments relative to the neurotoxic lesion are crucial for proper interpretation. In particular, although COX1 is the catalytic subunit of COX, increases in total COX activity cannot be equated with increases in COX1 gene expression. Also, the latent increase in overall COX activity seen after MPTP can reasonably be interpreted as altered electrical activity in thalamocortical basal ganglia circuitry subsequent to lesioning (Hirsch et al., 2000). Increases in mRNA
COX1 expression, which are sometimes transient (Périer et al., 2000) beginning $1 \mathrm{~d}$ after unilateral 6-OHDA lesions, are less easy to interpret, because they could represent either an ongoing neurotoxic process or a short-lived compensatory process. In contrast, reductions in basal ganglia COX activity 1 week after a striatal neurotoxic lesion (Levivier and Donaldson, 2000) are more likely related to neuronal destruction in the same region. Future studies will need to determine whether treatment with MPTP or 6-OHDA leads to changes in nigral COX1 mRNA expression (or expression of other COX subunits) within 12-24 hr after administration, similar to those observed after administration of a neurotoxic dose of METH. These studies would not only be of use in determining whether the present findings are generalizable, but they may also help in determining whether increases in COX1 mRNA after METH are a cause or consequence of DA neurotoxicity.

It is also of interest to note that two studies have previously reported changes in overall $\mathrm{COX}$ activity after a neurotoxic regimen of METH. In particular, Burrows and colleagues (2000b) used COX histochemistry to map metabolic activity after treatment with the neurotoxins, METH, and the structurally related amphetamine, methylenedioxymethamphetamine. Both drugs were associated with decreases in COX activity in the striatum and substantia nigra $2 \mathrm{hr}$ after drug administration (10 hr after the first dose), with normalization of activity within $24 \mathrm{hr}$. Although changes in $\mathrm{COX}$ activity were not shown to be directly linked to neurotoxicity, alterations in COX activity could be related to the increase in COX1 subunit expression documented in the present study. In a different study, Chapman et al. (2001) reported increased COX activity in the entopeduncular nucleus and substantia nigra 3 weeks after treatment with METH. Like the study by Burrows et al. (2000b), these data relate to COX activity in sum, as a marker of oxidative cellular metabolism, rather than expression, activity, or turnover of an individual subunit of the COX complex. Also, given that COX activity was assessed 3 weeks after METH, it is difficult to relate these changes to the early neurotoxic process, and, as discussed by Burrows et al. (2000b) and Chapman et al. (2001), the observed changes in COX activity most likely reflect changes in basal ganglia circuit activity.

Several potential limitations of the present study should be acknowledged. First, it is possible that the neuroprotective effects of cycloheximide and actinomycin-D are unrelated to their effects on protein synthesis and gene transcription but instead are caused by nonspecific effects. Although we have primarily addressed all known potential confounds (i.e., temperature, METH pharmacokinetics, and actions at the DAT), it is possible that other 

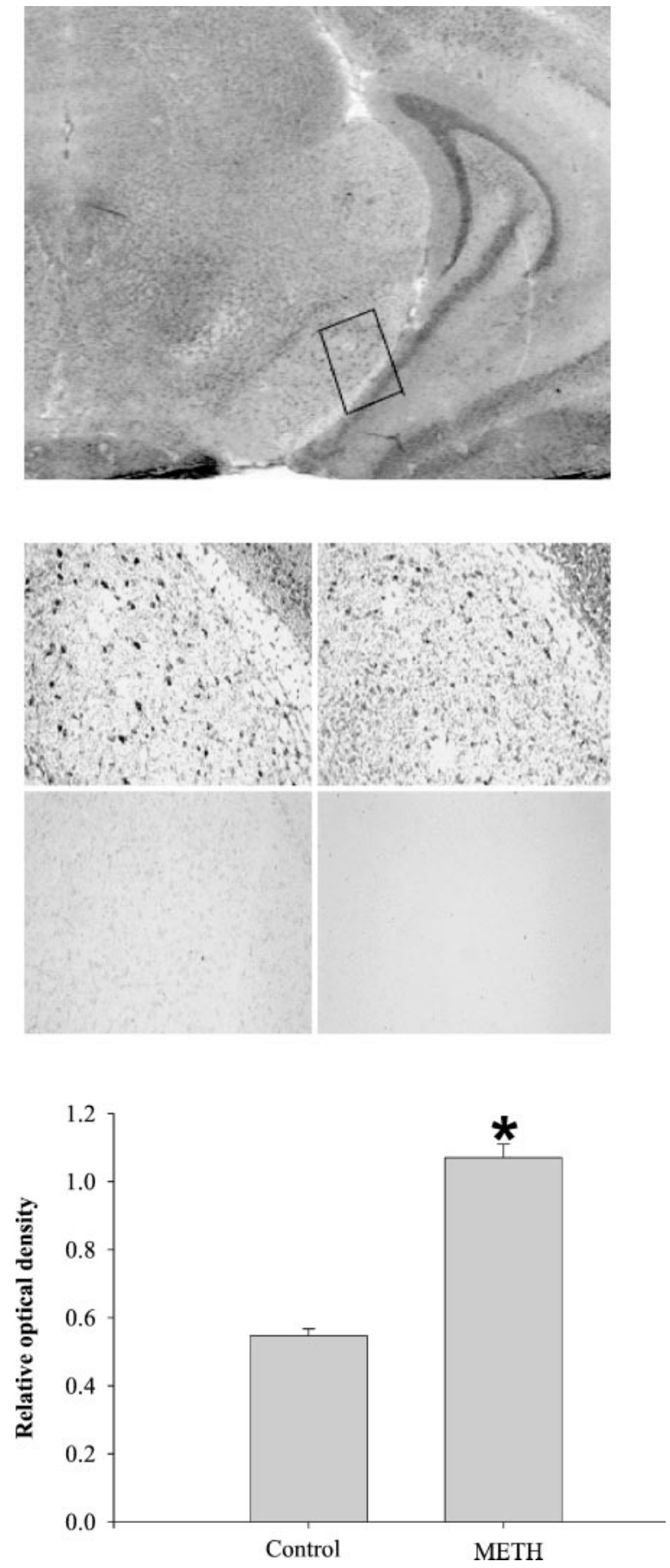

Figure 7. Representative of in situ hybridization image of COX1 mRNA in the substantia nigra pars reticulata, of mice treated with METH or saline $24 \mathrm{hr}$ previously. The method was as described in Materials and Methods. The orientation of the substantia nigra pars reticulata and the area of interest (box) amplified for quantitative analysis are shown in the top panel (amplification $60 \times$ ). Increased mRNA levels were observed in neurons after METH (middle panel, top left corner; amplification $250 \times$ ) compared with saline control (middle panel, top right corner) using COX1 antisense cRNA probes. Sense probe (middle panel, bottom left corner) and zero probe (without any probe; middle panel, bottom right corner) were also used in the METH sections as negative controls. Quantitative study of the COX1 mRNA expression showed a twofold increase in METHtreated mice compared with control, with $p<0.01$ (bottom panel, shown as *). Results shown represent the mean \pm SEM for each group $(n=20$ neurons per group). unknown effects of these drugs were responsible for their neuroprotective actions. Second, it should be emphasized that the gene expression studies were conducted using tissue only from the mouse ventral midbrain, leaving the possibility that observations are species and/or brain region specific. Other species and other brain regions, particularly the striatum, merit investigation to confirm and extend the present findings. Also, other brain regions need to be examined to assess the specificity of the observed COX1 changes and their relation to DA neurotoxicity. Third, it is important to bear in mind that in the array studies only twofold or greater changes in expression were considered, leaving open the possibility that smaller (less than twofold) yet critically important changes might be overlooked. Fourth, it is conceivable that the subtractive strategy using the DAT blocker WIN35,428 was flawed. Specifically, it is possible that by subtracting genes expressed after WIN35,428, given alone or in combination with METH, some genes linked to METH-induced DA release but not METH-induced DA neurotoxicity were included. This possibility must be considered because DAT inhibitors block not only METH-induced DA neurotoxicity but also METH-induced DA release, although there is evidence to suggest that METHinduced DA release and METH-induced DA neurotoxicity are linked (O'Dell et al., 1991). Finally, it is possible that genes essential to the neurotoxic process are not included on the DA microarray or neuronal microarrays and therefore were missed. Despite these potential limitations, the strategy used was successful in identifying several genes that appear to be linked to the neurotoxic process.

In sum, the present studies provide evidence that gene expression plays a fundamental role in METH-induced DA neurotoxicity. With use of microarray techniques, in combination with targeted pharmacological and physiologic methods, several genes that appear linked to the neurotoxic process have been identified, including COX1. Additional studies are needed to more fully delineate the precise role of COX1 in METH-induced DA neurotoxicity and to evaluate the role of the other gene expression changes shown here to occur during early phases of METHinduced DA neural injury.

\section{REFERENCES}

Albers DS, Sonsalla PK (1995) Methamphetamine-induced hyperthermia and dopaminergic neurotoxicity in mice: pharmacological profile of protective and nonprotective agents. J Pharmacol Exp Ther 275:1104-1114.

Ali SF, Newport RR, Holson W, Slikker Jr W, Bowyer JF (1995) Low environmental temperatures or pharmacologic agents that produce hyperthermia decrease methamphetamine neurotoxicity in mice. Ann NY Acad Sci 765:338.

Ali SF, Newport GD, Slikker Jr W (1996) Methamphetamine-induced dopaminergic toxicity in mice. Role of environmental temperature and pharmacological agents. Ann NY Acad Sci 801:187-198.

Badiani A, Oates MM, Day HE, Watson SJ, Akil H (1998) Amphetamine-induced behavior, dopamine release, and c-fos mRNA expression: modulation by environmental novelty. $\mathrm{J}$ Neurosci 18:10579-10593.

Badiani A, Oates MM, Day HE, Watson SJ, Akil H, Robinson TE (1999) Environmental modulation of amphetamine-induced c-fos expression in D1 versus D2 striatal neurons. Behav Brain Res 103:203-209.

Barrett T, Xie T, Piao Y, Dillon-Carter O, Kargul GJ, Lim MK, Chrest FJ, Wersto R, Rowley DL, Juhaszova M, Zhou L, Vawter MP, Becker KG, Cheadle C, Wood III WH, McCann UD, Freed WJ, Ko MS, Ricaurte GA, Donovan DM (2001) A murine dopamine neuronspecific cDNA library and microarray: increased COX I expression during methamphetamine neurotoxicity. Neurobiol Dis 8:822-833.

Bezard E, Jaber M, Gonon F, Boireau A, Bloch B, Gross CE (2000) Adaptive changes in the nigrostriatal pathway in response to increased 1-methyl-4-phenyl-1,2,3,6-tetrahydropyridine-induced neurodegeneration in the mouse. Eur J Neurosci 12:2892-2900.

Bibb MJ, Van Etten RA, Wright CT, Walberg MW, Clayton DA (1981) 
Sequence and gene organization of mouse mitochondrial DNA. Cell 26:167-180.

Bowyer JF, Tank AW, Newport GD, Slikker Jr W, Ali SF, Holson RR (1992) The influence of environmental temperature on the transient effect of methamphetamine on dopamine levels and dopamine release in striatum. J Pharmacol Exp Ther 260:817-824.

Bowyer JF, Davies DL, Schmued L, Broening HW, Newport GD, Slikker Jr W, Holson RR (1994) Further studies of the role of hyperthermia in methamphetamine neurotoxicity. J Pharmacol Exp Ther 268:15711580 .

Burrows KB, Nixdorf WL, Yamamoto BK (2000a) Central administration of methamphetamine synergizes with metabolic inhibition to deplete striatal monoamines. J Pharmacol Exp Ther 292:853-860.

Burrows KB, Gudelsky G, Yamamoto BK (2000b) Rapid and transient inhibition of mitochondrial function following methamphetamine or 3,4-methylenedioxymethamphetamine administration. Eur J Pharmacol 398:11-18.

Cadet JL, Jayanthi S, McCoy MT, Vawter M, Ladenheim B (2001) Temporal profiling of methamphetamine-induced changes in gene expression in the mouse brain: evidence from cDNA array. Synapse $41: 40-48$.

Callahan B, Yuan J, Stover G, Hatzidimitriou G, Ricaurte GA (1998) Effects of 2-deoxy-D-glucose on methamphetamine-induced dopamine and serotonin neurotoxicity. J Neurochem 70:190-197.

Callahan BT, Yuan J, Ricaurte GA (2001) Inhibitors of $\mathrm{Na} / \mathrm{H}^{+}$and $\mathrm{Na} / \mathrm{Ca}^{++}$exchange potentiate methamphetamine-induced dopamine neurotoxicity: possible role of ionic dysregulation in methamphetamine neurotoxicity. J Neurochem 77:1348-1361.

Chapman DE, Hanson GR, Kesner RP, Keefe KA (2001) Long-term changes in basal ganglia function after a neurotoxic regimen of methamphetamine. J Pharmacol Exp Ther 296:520-527.

Chesselet MF, Weiss L, Wuenschell C, Tobin AJ, Affolter HU (1987) Comparative distribution of mRNAs for glutamic acid decarboxylase, tyrosine hydroxylase, and tachykinins in the basal ganglia: an in situ hybridization study in the rodent brain. J Comp Neurol 262:125-140.

Finnegan KT, Karler R (1992) Role for protein synthesis in the neurotoxic effects of methamphetamine in mice and rats. Brain Res 591:160-164

Fumagalli F, Gainetdinov RR, Valenzano KJ, Caron MG (1998) Role of dopamine transporter in methamphetamine-induced neurotoxicity: evidence from mice lacking the transporter. J Neurosci 18:4861-4869.

Gibb JW, Hanson GR, Johnson M (1994) Neurochemical mechanisms of toxicity. In: Amphetamine and its analogs (Cho AK, Segal DS, eds), pp 269-295. Los Angeles: Academic.

González-Hernández T, Rodríguez M (2000) Compartmental organization and chemical profile of dopaminergic and GABA neurons in the substantia nigra of the rat. J Comp Neurol 421:107-135.

Hatzidimitriou G, McCann UD, Ricaurte GA (1999) Altered serotonin innervation patterns in the forebrain of monkeys treated with $(+) 3,4-$ methylenedioxymethamphetamine seven years previously: factors influencing abnormal recovery. J Neurosci 19:5096-5107.

Heffner TG, Hartman JA, Seiden LS (1980) A rapid method for the regional dissection of the rat brain. Pharmacol Biochem Behav 13:453-456.

Hirsch EC, Périer C, Orieux G, Francois C, Féger J, Yelnik J, Vila M, Levy R, Tolosa ES, Marin C, Herrero MT, Obeso JA, Agid Y (2000) Metabolic effects of nigrostriatal denervation in basal ganglia. Trends Neurosci 23[Suppl]::S78-S85.

Huang NK, Wan FJ, Tseng CJ, Tung CS (1997) Nicotinamide attenuates methamphetamine-induced striatal dopamine depletion in rats. NeuroReport 8:1883-1885.

Jayanthi IN, Krasnova B, Ladenheim B, Cadet JL (1999) Differential gene expression in methamphetamine neurotoxicity identified using cDNA arrays. Soc Neurosci Abstr 25:39.

Kerner JA, Standaert DG, Penney Jr JB, Young AB, Landwehrmeyer GB (1998) Simultaneous isotopic and nonisotopic in situ hybridization histochemistry with cRNA probes. Brain Res Brain Res Protoc 3:22-32.

Kim S, Westphalen R, Callahan B, Hatzidimitriou G, Yuan J, Ricaurte GA (2000) Toward the development of an in vitro model of methamphetamine-induced dopamine nerve terminal toxicity. J Pharmacol Exp Ther 293:625-633.

Kodama M, Akiyama K, Ujike H, Shimizu Y, Tanaka Y, Kuroda S (1998) A robust increase in expression of arc gene, an effector immediate early gene, in the rat brain after acute and chronic methamphetamine administration. Brain Res 796:273-283.

Kuperman DI, Freyaldenhoven TE, Schmued LC, Ali SF (1997) Methamphetamine-induced hyperthermia in mice: examination of dopamine depletion and heat-shock protein induction. Brain Res 771:221-227.
Levivier M, Donaldson D (2000) Metabolic changes after injection of quinolinic acid or 6-hydroxydopamine in the rat striatum: a time-course study using cytochrome oxidase and glycogene phosphorylase $a$ histochemistry. Neurol Res 22:425-429.

Lew R, Malberg JE, Ricaurte GA, Seiden LS (1997) Evidence for and mechanism of action of neurotoxicity of amphetamine related compounds. In: Highly selective neurotoxins: basic and clinical applications (Kostrzewa RM, ed), pp 235-268. Totowa, NJ: Humana.

Lowry OH, Rosenbrough NJ, Farr AL, Randall RJ (1951) Protein measurements with Folin phenol reagent. J Biol Chem 193:265-275.

Marek GJ, Vosmer G, Seiden LS (1990a) Dopamine uptake inhibitors block long-term neurotoxic effects of methamphetamine upon dopaminergic neurons. Brain Res 513:274-279.

Marek GJ, Vosmer G, Seiden LS (1990b) The effects of monoamine uptake inhibitors and methamphetamine on neostriatal 6-hydroxydopamine (6-OHDA) formation, short-term monoamine depletions and locomotor activity in the rat. Brain Res 516:1-7.

Merchant KM, Hanson GR, Dorsa DM (1994) Induction of neurotensin and c-fos mRNA in distinct subregions of rat neostriatum after acute methamphetamine: comparison with acute haloperidol effects. J Pharmacol Exp Ther 269:806-812.

Miller DB, O'Callaghan JP (1994) Environment, stress- and druginduced alterations in body temperature affect the neurotoxicity of the substituted amphetamines in the C57BL/6J mouse. J Pharmacol Exp Ther 270:752-760.

O'Dell SJ, Weihmuller FB, Marshall JF (1991) Multiple methamphetamine injections induce marked increases in extracellular striatal dopamine which correlate with subsequent neurotoxicity. Brain Res $564: 256-260$.

Périer C, Vila M, Féger J, Agid Y, Hirsch EC (2000) Functional activity of zona incerta neurons is altered after nigrostriatal denervation in hemiparkinsonian rats. Exp Neurol 162:214-224.

$\mathrm{Pu}$ C, Fisher JE, Cappon GD, Vorhees CV (1994) The effects of amfonelic acid, a dopamine uptake inhibitor, on methamphetamineinduced dopaminergic terminal degeneration and astrocytic response in rat striatum. Brain Res 649:217-224.

Ricaurte GA, Guillery RW, Seiden LS, Schuster CR, Moore RY (1982) Dopamine nerve terminal degeneration produced by high doses of methylamphetamine in the rat brain. Brain Res 235:93-103.

Ricaurte GA, Guillery RW, Seiden LS, Schuster CR (1984) Nerve terminal degeneration after a single injection of D-amphetamine in iprindole-treated rats: relation to selective long-lasting dopamine depletion. Brain Res 291:378-382.

Ricaurte GA, Martello AL, Katz JL, Martello MB (1992) Lasting effects of $( \pm)$ 3,4-methylenedioxymethamphetamine (MDMA) on central serotonergic neurons in nonhuman primates: neurochemical observations. J Pharmacol Exp Ther 261:616-621.

Sheng P, Ladenheim B, Moran TH, Wang XB, Cadet JL (1996) Methamphetamine-induced neurotoxicity is associated with increased striatal AP-1 DNA-binding activity in mice. Brain Res Mol Brain Res 42:171-174

Smith AJ, McGinty JF (1994) Acute amphetamine or methamphetamine alters opiod peptide mRNA expression in rat striatum. Brain Res Mol Brain Res 21:359-362.

Stephans SE, Whittingham TS, Douglas AJ, Lust WD, Yamamoto BK (1998) Substrates of energy metabolism attenuate methamphetamineinduced neurotoxicity in striatum. J Neurochem 71:613-621.

Vila M, Perier C, Feger J, Yelnik J, Faucheux B, Ruberg M, RaismanVozari R, Agid Y, Hirsch EC (2000) Evolution of changes in neuronal activity in the subthalamic nucleus of rats with unilateral lesion of the substantia nigra assessed by metabolic and electrophysiological measurements. Eur J Neurosci 12:337-344.

Wang JQ, McGinty JF (1995) Dose-dependent alteration in zif/268 and preprodynorphin mRNA expression induced by amphetamine or methamphetamine in rat forebrain. J Pharmacol Exp Ther 273:909-917.

Whitney LW, Becker K, Tresser NJ, Caballero-Ramos CI, Munson P, Prabhu VV, Trent JM, McFarland HF, Biddison WE (1999) Analysis of gene expression in multiple sclerosis lesions using cDNA microarrays. Ann Neurol 46:425-428.

Xie T, Ho SL, Ramsden D (1999) Characterization and implications of estrogenic down-regulation of human catechol-O-methyltransferase gene transcription. Mol Pharmacol 56:31-38.

Xie T, McCann UD, Kim S, Yuan J, Ricaurte GA (2000) Effect of temperature on dopamine transporter function and intracellular accumulation of methamphetamine: implications for methamphetamineinduced dopaminergic neurotoxicity. J Neurosci 20:7838-7845.

Yuan J, Callahan BT, McCann UD, Ricaurte GA (2001) Evidence against an essential role of endogenous brain dopamine in methamphetamine-induced dopaminergic neurotoxicity. J Neurochem 77:1338-1347. 